\title{
ALLERGY TO ORTHOPEDIC METAL IMPLANTS - PROSPECTIVE STUDY
}

\author{
BEATA KRĘCISZ, MARTA KIEĆ-ŚWIERCZYŃSKA, and DOROTA CHOMICZEWSKA-SKÓRA
}

\author{
Nofer Institute of Occupational Medicine, Łódź, Poland \\ Center of Occupational Allergy and Environmental Health
}

\begin{abstract}
Objectives: Evaluation of the allergenic properties of the metal knee or hip joint implants 24 months post surgery and assessment of the relation between allergy to metals and metal implants failure. Materials and Methods: The study was conducted in two stages. Stage I (pre-implantation) - 60 patients scheduled for arthroplasty surgery. Personal interview, dermatological examination and patch testing with $0.5 \%$ potassium dichromate, $1.0 \%$ cobalt chloride, $5.0 \%$ nickel sulfate, $2.0 \%$ copper sulfate, $2.0 \%$ palladium chloride, $100 \%$ aluminum, $1 \%$ vanadium chloride, $5 \%$ vanadium, $10 \%$ titanium oxide, $5 \%$ molybdenum and $1 \%$ ammonium molybdate tetrahydrate were performed. Stage II (post-surgery) - 48 subjects participated in the same procedures as those conducted in Stage I. Results: Stage I - symptoms of "metal dermatitis" were found in $21.7 \%$ of the subjects: $27.9 \%$ of the females, $5.9 \%$ of the males. Positive patch test results were found in $21.7 \%$ of the participants, namely to: nickel (20.0\%); palladium (13.3\%); cobalt (10.0\%); and chromium (5.9\%). The allergy to metals was confirmed by patch testing in $84.6 \%$ of the subjects with a history of metal dermatitis. Stage II $-10.4 \%$ of the participants complained about implant intolerance, $4.2 \%$ of the examined persons reported skin lesions. Contact allergy to metals was found in $25.0 \%$ of the patients: nickel $20.8 \%$, palladium $10.4 \%$, cobalt $16.7 \%$, chromium $8.3 \%$, vanadium $2.1 \%$ Positive post-surgery patch tests results were observed in $10.4 \%$ of the patients. The statistical analysis of the pre- and post-surgery patch tests results showed that chromium and cobalt can be allergenic in implants. Conclusions: Metal orthopedic implants may be the primary cause of allergies. that may lead to implant failure. Patch tests screening should be obligatory prior to providing implants to patients reporting symptoms of metal dermatitis. People with confirmed allergies to metals should be provided with implants free from allergenic metals.
\end{abstract}

Key words:

Orthopedic implants, Allergy to metals, Contact dermatitis, Patch tests

\section{INTRODUCTION}

Metal implants are widely used in the treatment of the musculoskeletal system.

The prevalence of hip osteoarthritis is approximately $7.4 \%$ and knee osteoarthritis $12.2 \%$ in the general population. The estimated appropriateness rate for hip and knee replacement was $37.7 \%$ in men and $52.7 \%$ in women and $11.8 \%$ in men and $17.9 \%$ in women with osteoarthritis, respectively [1].

Joint implants are usually made of stainless steel containing nickel (13-15\%), chromium (17-19\%) and also cobalt-chromium alloys (62-67\% cobalt, 27-30\% chromium) as well as titanium-aluminum alloys (81-91\% titanium, 5.5-6.5\% aluminum) [2-4]. However, Holzwarth et al. [5] emphasize that the same types of alloys can vary in their chemical composition. Although the currently used metallic implants of the new generation have much better physical properties and are more resistant to corrosion and abrasion, the number of complications after arthroplasty and unsatisfactory outcomes make from 5\% to $10 \%$ [6,7]. Intolerance reactions to metal implants may be manifested as dermatitis, impaired wound healing, effusions, pain,

Received: April 2, 2012. Accepted: April 5, 2012

Address reprint request to B. Kręcisz, Center of Occupational Allergy and Environmental Health, Nofer Institute of Occupational Medicine, św. Teresy 8, 91-348 Łódź, Poland (e-mail: krecisz@imp.lodz.pl). 
or loosening [8]. Some authors believe that some causes of intolerance to metal alloys may be attributable to allergic reactions to the implanted metals [8,9], whereas others do not share this view $[10,11]$. Furthermore, there is no consensus among the authors on the need for allergy screening to metals prior to the surgery $[12,13]$.

The aims of the study were: to evaluate the allergenic properties of the metal knee and hip implants 24 months after surgery and to assess the relation between allergy to metals and metal implants failure.

\section{MATERIALS AND METHODS}

The study was conducted in two stages.

\section{Stage I - before implantation}

The study included 60 patients (43 women and $17 \mathrm{men}$ ) whose mean age equaled 61.7 years. Thirty-nine patients (27 women, 12 men) were scheduled for hip arthroplasty surgery and 21 persons (16 women and 5 men) for the knee joint arthroplasty surgery. All the participants had the following performed:

- personal interview with particular emphasis on the symptoms of the cutaneous intolerance reactions to metal accessories upon direct contact with the skin, including itching, burning, and eczematous reaction (the so-called "metal dermatitis") or dermatitis due to exposure to leather accessories - (it was proven that chromium is found in various leather products, which may result in sensitization) [14];

- dermatological examination;

- patch tests.

The set of substances used for the purpose of the patch tests contained the most popular metals that are used in various implants: $0.5 \%$ potassium dichromate, $1.0 \%$ cobalt chloride, $5.0 \%$ nickel sulfate, $2.0 \%$ copper sulfate, $2.0 \%$ palladium chloride, $100 \%$ aluminum, $1 \%$ vanadium (III) chloride, $5 \%$ vanadium, $10 \%$ titanium (IV) oxide, 5\% molybdenum and 1\% ammonium molybdate (VI) tetrahydrate. All allergens were dispersed in petrolatum, with the exception of ammonium molybdate (VI) tetrahydrate, which was dispersed in water. The tests were performed using IQ Chambers. Both the allergens and the chambers were supplied by Chemotechnique Diagnostics, Vellinge, Sweden. The results were evaluated according to the recommendations of the International Contact Dermatitis Research Group [15]. The readings were made two and four days after the application of the tests. The skin reactions were classified as follows: 0 - negative reactions; "+" - erythema and edema; "++" - erythema and edema with papules and vesicles confined within the chamber; " +++ " - erythema with vesicles and papules extending beyond the chamber; and IR, irritant reaction.

The patients with diagnosed allergy to metals were advised to receive implants that did not contain the respective metals causing allergy.

\section{Stage II - mean time 24 months $(\mathrm{SD}=\mathbf{0 . 5 2})$ after implantation}

All 60 participants of the first Stage were invited to participate in Stage II of the study. Forty-eight people, including 36 women and 12 men took part in the examination. Personal interview was carried out in the case of all participants, with particular emphasis on the implant metal tolerance. Furthermore, the dermatological examination and patch tests (the same as those used in Stage I) were performed.

\section{Statistical analysis}

Statistical inference was conducted at the significance level of 0.05 using two-tailed tests.

The evaluation of the difference in the frequency of sensitization to metals before inserting the implant and after the implant had been inserted was conducted by the Fisher's exact test. 
The changes in the incidence of sensitization after the insertion of the implant were compared with the GEE regression model (GeneralizedEstimatingEquation) with a binomial distribution for the distribution of the dependent variable. All statistical calculations were made using package $\mathrm{R}$.

\section{ETHICS}

The study protocol was approved by the local Biomedical Ethics Committee (Decision No. 24/2005).

\section{RESULTS}

\section{Stage I}

Personal interview: symptoms of "metal dermatitis" or dermatitis due to exposure to leather accessories were found in 13 (21.7\%) subjects: 12 females (27.9\%) and 1 male $(5.9 \%)$.

1. In the course of the dermatological examination, current skin lesions were found in $4(6.7 \%)$ subjects: 3 females and 1 male. These included: signs of psoriasis, hand eczema, leg eczema and ichthyosis.

2. Patch tests results: contact allergy to metals (at least one positive response to a patch test) was found in 13 subjects (21.7\%): 10 females $(23.2 \%)$ and 3 males $(17.5 \%)$. In general, there were 30 positive results of patch tests ( 27 in females, 3 in males). The results of patch testing are shown in Table 1. Allergy to metals was confirmed by patch testing in 11 out of the 13 subjects $(84.6 \%)$ with a history of metal dermatitis or dermatitis due to exposure to leather accessories (10 females and 1 male).

The prevalence of sensitization to all of the examined metals among the female subjects was significantly higher than among the males, $p=0.05$. However, there is no statistically significant difference in the sensitivities of the particular metals between women and men: $\mathrm{p}=0.48(\mathrm{Ni})$; $\mathrm{p}=0.09(\mathrm{Pd}) ; \mathrm{p}=0.17(\mathrm{Co}) ; \mathrm{p}=1.0(\mathrm{Cr})$.

\section{Stage II}

The participation rate in the second course of examination was $80.0 \%$ (48 persons: 36 females and 12 males). Among the other 12 participants: three people died of various causes and 9 refused to be reexamined.

1. Personal interview: 5 participants (4 females, 1 male) $(10.4 \%)$ (3 with hip joint implants and 2 with knee joint implants) complained about pain and recurring inflammations of tissues around the implants, 2 persons $(4.2 \%)$ reported periodical skin lesions, which appeared circa one year after the surgery was performed. However, those 2 persons did not suffer from the complications around the implant. None of the patients with confirmed allergy to metals prior to the surgery reported symptoms associated with the use of the implant they had received. The implants were supposed

Table 1. Positive results of patch tests in patients before and 24 months after the surgery

\begin{tabular}{|c|c|c|c|c|c|c|}
\hline \multirow{2}{*}{ Allergen } & \multicolumn{3}{|c|}{$\begin{array}{c}\text { Before surgery } \\
\mathrm{n}(\%)\end{array}$} & \multicolumn{3}{|c|}{$\begin{array}{c}\text { After surgery } \\
\mathrm{n}(\%)\end{array}$} \\
\hline & $\begin{array}{l}\text { females } \\
(\mathrm{N}=43)\end{array}$ & $\begin{array}{c}\text { males } \\
(\mathrm{N}=17)\end{array}$ & $\begin{array}{c}\text { total } \\
(\mathrm{N}=60)\end{array}$ & $\begin{array}{c}\text { females } \\
(\mathrm{N}=36)\end{array}$ & $\begin{array}{c}\text { males } \\
(\mathrm{N}=12)\end{array}$ & $\begin{array}{c}\text { total } \\
(\mathrm{N}=48)\end{array}$ \\
\hline Nickel sulfate 5\% & $10(23.2)$ & $2(11.8)$ & $12(20.0)$ & $10(27.8)$ & $0(0)$ & $10(20.8)$ \\
\hline Palladium chloride $2 \%$ & $8(18.6)$ & $0(0)$ & $8(13.3)$ & $5(13.9)$ & $0(0)$ & $5(10.4)$ \\
\hline Cobalt chloride $1 \%$ & $6(13.9)$ & $0(0)$ & $6(10.0)$ & $8(22.2)$ & $0(0)$ & $8(16.7)$ \\
\hline Potassium dichromate $0.5 \%$ & $2(4.6)$ & $1(5.9)$ & $3(5.0)$ & $4(11.1)$ & $0(0)$ & $4(8.3)$ \\
\hline Vanadium chloride $1 \%$ & $0(0)$ & $0(0)$ & $0(0)$ & $1(2.8)$ & $0(0)$ & $1(2.1)$ \\
\hline
\end{tabular}


Table 2. The list of participants (only females) with positive patch test results who were tested before and after the implant surgery

\begin{tabular}{|c|c|c|c|c|}
\hline \multirow{2}{*}{$\begin{array}{c}\text { No. } \\
\text { of patient }\end{array}$} & \multicolumn{2}{|c|}{ Before surgery } & \multicolumn{2}{|c|}{ After surgery } \\
\hline & results of patch tests & type of joint replacement & results of patch tests & $\begin{array}{l}\text { symptoms of implant } \\
\text { intolerance }\end{array}$ \\
\hline 1 & negative & hip & Co & periodical skin lesions \\
\hline 2 & negative & hip & $\mathrm{Ni}$ & periodical skin lesions \\
\hline 3 & negative & hip & $\mathrm{Ni}, \mathrm{Co}$ & pain, swelling, erythema \\
\hline 4 & negative & hip & $\mathrm{Ni}, \mathrm{Co}, \mathrm{Cr}$ & pain, swelling, erythema \\
\hline 5 & negative & knee & $\mathrm{Cr}$ & pain, swelling, erythema \\
\hline 6 & $\mathrm{Ni}$ & knee & $\mathrm{Ni}, \mathrm{Co}, \mathrm{Cr}, \mathrm{Cu}, \mathrm{V}$ & symptom-free \\
\hline 7 & $\mathrm{Ni}, \mathrm{Pd}$ & hip & $\mathrm{Ni}, \mathrm{Pd}$ & symptom-free \\
\hline 8 & $\mathrm{Ni}, \mathrm{Pd}$ & knee & $\mathrm{Ni}, \mathrm{Pd}$ & symptom-free \\
\hline 9 & $\mathrm{Ni}, \mathrm{Pd}, \mathrm{Co}$ & hip & $\mathrm{Ni}, \mathrm{Pd}, \mathrm{Co}, \mathrm{Cr}$ & symptom-free \\
\hline 10 & $\mathrm{Ni}, \mathrm{Co}, \mathrm{Cr}, \mathrm{Cu}$ & hip & $\mathrm{Ni}, \mathrm{Co}, \mathrm{Cr}, \mathrm{Cu}$ & symptom-free \\
\hline 11 & $\mathrm{Ni}, \mathrm{Pd}$ & hip & $\mathrm{Ni}, \mathrm{Pd}, \mathrm{Co}$ & symptom-free \\
\hline 12 & $\mathrm{Ni}, \mathrm{Pd}, \mathrm{Co}$ & hip & $\mathrm{Ni}, \mathrm{Pd}, \mathrm{Co}$ & symptom-free \\
\hline
\end{tabular}

not to contain allergenic metals to which the patients were sensitized.

2. The dermatological examination: 3 women ( 2 with the hip implant, and 1 with the implant of the knee) had inflammation around the implant tissues. Two other women suffered from skin diseases. One woman had a wrist eczema in the adhesion place of a metal watch, the other had an ichthyosis.

3. Patch tests results: contact allergy to metals (at least one positive response to a patch test) was found in 12 subjects $(25.0 \%)$, all of whom were females $(33.3 \%)$. There was no statistically significant difference between the frequency of allergy to metals before and after the surgery. In total, 31 positive results were recorded. Table 1 summarizes the results of the patch tests in Stage I and in Stage II of the study. Positive patch tests results, which appeared after the operation, were observed in 5 patients $(10.4 \%)$ including $3(6.25 \%)$ with pain, swelling and erythema around the implant and 2 cases with periodic eczematous skin lesions. In all these cases there was a confirmed presence of allergenic metals in the used implants. Furthermore, 3 women with positive pre-implantation tests developed subsequent allergy to metals (while the implants were welltolerated). In contrast to this, in one woman and in one man who reported recurrent inflammation around the implant, the patch tests to metals were negative. The statistical analysis of the patch tests results which were obtained before and after the surgery showed that chromium and cobalt can be allergenic when used in the implant $-\mathrm{p}=0.05$ and $\mathrm{p}=0.02$, respectively. Table 2 presents the list of participants with positive patch tests results who were tested before and after the implant surgery.

\section{DISCUSSION}

The role of allergy to implants is controversial. The number of prospective studies is limited and the results differ. For example: in one examination it was shown that only 3 out of $112(2.7 \%)$ patients with metal-to-metal total hip arthroplasties were allergic to metals [16]. In other studies, 5 out of $72(6.9 \%)$ patients developed allergic reactions to at least one or more metals that were included in the orthopedic 
implant one year post-implantation [17]. Furthermore, Waterman et al. [18] noted positive tests results in 8 out of $85(9.4 \%)$ patients undergoing hip replacement. Our results are most similar to the latter and suggest that the implant could be a source of primary sensitization to metals. Five out of $48(10.4 \%)$ patients had positive tests results for at least one metal (2 tests with chromium, 3 tests with nickel and cobalt). In addition, 3 pre-implantation-positive women subsequently developed allergy to metals. The statistical analysis of the patch tests results which were obtained before and after the surgery shows that chromium and cobalt can be allergenic when used in the implant.

It is currently unclear whether metal sensitivity is a contributing factor to the implant failure. Carlsson et al. [19] report that, despite the presence of metal allergy, the implanted material is often well tolerated. Similarly, Tyssen et al. [10] showed that the risk of surgical revision was not increased in patients with metal allergies. Hallab et al. [20] in the accumulated reports on metal allergy in total hip arthroplasty patients indicated that the prevalence of metal allergy was approximately $25 \%$ among the patients with a well-functioning hip arthroplastic implant and $60 \%$ among the patients with a failed or poorly functioning device. In our study, in three persons who became allergic to metal during the implant use, recurrent pain, swelling and erythema around the implant were observed. Two other participants developed symptoms of metal dermatitis. In all those cases, the presence of sensitizing metals in the implants was confirmed. Also, the role of allergy to metal in implant failure was suggested in our previous observations [21] and in the study of German authors [8], who reported four cases of women with poor tolerance to knee implants (pain, recurrent effusions, symptoms of cutaneous metal intolerance). Those women were allergic to nickel and cobalt, but after switching to titanium-plated endoprosthesis they became symptom-free.

Another debatable issue is whether patch tests are useful prior to arthroplastic surgery.
Some researchers agree that individuals without a reported history of metal dermatitis need not be screened prior to implantation [12,22]. What is more, pre-implant screening is not performed routinely in Sweden or Denmark for any patients, and it is not systematically done in other locations either [13]. On the other hand, Kieffer et al. [23] suggest that patient's self-history of metal reactions is not sufficiently predictive to justify patch testing and that the prevalence of reactions is high enough to justify pre-implant evaluation. In our examination performed pre-surgery, allergy to at least one metal was present in $21.7 \%$ of the participants $(23.2 \%$ of the females and $17.5 \%$ of the males). The prevalence was higher than that recorded in the general population. It is estimated that up to $17 \%$ of women and $3 \%$ of men are allergic to nickel, and that about 1 to $2 \%$ are allergic to cobalt, chromium, or both [24].

The higher incidence of allergies in the examined group may be due to the fact that $21.7 \%$ of the subjects $(27.9 \%$ female, $5.9 \%$ - male ones) reported symptoms of "metal dermatitis" or dermatitis due to exposure to leather accessories and, therefore, it can be assumed that they were more willing to participate in the study. The advantage of using allergy screening prior to device implantation is supported by the fact that none of the metal-allergic participants implanted with a prosthesis free of the offending materials (we have to believe this, because in some cases we were not provided with the implant passport) showed signs of implant intolerance.

Noteworthy is the fact that in $84.6 \%$ of the participants with symptoms of "metal dermatitis" or dermatitis due to the exposure to leather accessories, allergy to metals was confirmed by patch testing. Similar results were obtained by Reed et al. [25]. These experiments indicate the importance of detailed personal interview on metal dermatitis or dermatitis caused by the exposure to leather accessories in the identification of patients with allergy to metals. 


\section{CONCLUSIONS}

Our results suggest that:

1. Metal orthopedic implants, in particular those containing chromium and cobalt, may be the primary cause of allergies.

2. Allergy to the components of orthopedic devices may be the cause of implant failure.

3. Detailed history-taking on metal dermatitis or dermatitis caused by the exposure to leather accessories is helpful in identifying patients who are allergic to metals.

4. Patch tests screening should be obligatory prior to device implantation in patients reporting the symptoms of metal dermatitis or dermatitis due to the exposure to leather accessories.

5. People with confirmed allergies to metals should be provided with implants which do not contain allergenic metals.

\section{REFERENCES}

1. Quintana JM, Arostequi I, Escobar A, Azkarate J, Goenaga I, Lafuente I. Prevalence of knee and hip osteoarthritis and appropriateness of joint replacement in older population. Arch Intern Med 2008;168:1576-84.

2. Basko-Plluska JL, Thyssen JP, Schalock PC. Cutaneous and systemic hypersensitivity reactions to metallic implants. Dermatitis 2011;22:65-79.

3. 316/316L stainless steel. Product data sheet [cited 2011 December 15]. Available from URL: http:/www.aksteel.com/ PDF/markets_products/stainless/austenitic/316_316L_Data_ Sheet.pdf.

4. Disegi JA, Eschbach L. Stainless steel in bone surgery. Int J Care Injured 2000;31(Suppl 4):2-6.

5. Holzwarth U, Thomas P, Kachler W, Göske J, Schnuch A. Metallurgical differentiation of cobalt-chromium alloys for implants. Orthopade 2005;34:1046-51.

6. Gawkrodger DJ. Metal sensitivities and orthopaedic implants revised: The potential for metal allergy with the new metal-onmetal joint prostheses. Br J Dermatol 2003;148:1089-93.
7. Simpson JM, Villar RN. Hip resurfacing. Br Med J 2010;341:3459.

8. Dietrich K-A, Mazoochian F, Summer B, Reinert M, Ruzicka T, Thomas P. Intolerance reactions to knee arthroplasty in patients with nickel/cobalt allergy and disappearance of symptoms after revision surgery with titanium-based endoprostheses. JDDG 2009;7:410-3.

9. Niki Y, Matsumoto H, Otani T, Yatabe T, Kondo M, Yoshimine F, et al. Screening for symptomatic metal sensitivity: A prospective study of 92 patients undergoing total knee arthroplasty. Biomaterials 2006;26:1019-26.

10. Thyssen JP, Jacobsen SS, Engkilde K, Johansen JD, Søballe K, Menné T. The association between metal allergy, total hip arthroplasty and revision. Acta Orthop 2009;80:646-52.

11. Gawkrodger DJ. Nickel sensitivity and the implantation of orthopaedic prostheses. Contact Dermatitis 1993;28:257-9.

12. Thyssen JP, Menné T, Schalock PC, Taylor JS, Maibach HI. Pragmatic approach to the clinical work-up of patients with putative allergic disease to metallic orthopaedic implants before and after surgery. Br J Dermatol 2011;164:473-8.

13. Bruze M. Thoughts on implants and contact allergy. Arch Dermatol 2008;144:1042-4.

14. Rydin S. Investigation of the content of $\mathrm{Cr}(\mathrm{VI})$ and $\mathrm{Cr}(\mathrm{III})$ in leather products on the Danish market. Survey of Chemical Substances in Consumer Products. Survey no. 3. Danish Environmental Protection Agency, Danish Ministry of the Environment; 2002.

15. Wahlberg JE. Patch testing. In: Rycroft RJG, Menné T, Frosch PJ, Lepoittevin JP, editors. Textbook of contact dermatitis. 3rd edition. Berlin: Springer; 2001. p. 439-68.

16. Carlsson AS, Magnusson B, Möller H. Metal sensitivity in patients with metal-to metal total hip arthroplasties. Acta Orthop Scand 1980;51:57-62.

17. Frigerio E, Piagatto PD, Guzzi G, Altomare G. Metal sensitivity in patients with orthopaedic implants: A prospective study. Contact Dermatitis 2011;64:273-9.

18. Waterman AH, Schrik JJ. Allergy in hip arthroplasty. Contact Dermatitis 1985;13:294-301. 
19. Carlsson A, Möller H. Implantation of orthopaedic device in patients with metal allergy. Acta Derm Venereol 1989;69: 62-6.

20. Hallab N, Merrit K, Jacobs JJ. Metal sensitivity in patients with orthopaedic implants. J Bone Joint Surg Am 2001;83:428-36.

21. Kręcisz B, Kieć-Świerczyńska M, Bąkowicz-Mitura K. Allergy to metals as a cause of orthopedic implant failure. Int J Occup Med Environ Health 2006;19:178-80.

22. Schalock PC, Menné T, Johansen JD, Taylor JS, Maibach HI, Lindén C, et al. Hypersensitivity reactions to metallic implants - diagnostic algorithm and suggested patch test series for clinical use. Contact Dermatitis 2011;66:4-19.

23. Kieffer M. Nickel sensitivity: relationship between history and patch test reactions. Contact Dermatitis 1979;5:398-401.

24. Thyssen JP, Linneberg A, Menné T, Johansen JD. The epidemiology of contact allergy in the general population - prevalence and main findings. Contact Dermatitis 2007;57:287-99. 25. Reed KB, Davis MD, Nakamura K, Hanson L, Richardson DM. Retrospective evaluation of patch testing before or after metal device implantation. Arch Dermatol 2008;144:999-1007.

This work is available in Open Access model and licensed under a Creative Commons Attribution-NonCommercial 3.0 Poland License - http://creativecommons.org/ licenses/by-nc/3.0/pl/deed.en. 